\title{
Evaluation Model of Venous Industry Park Location Based on Fuzzy Analytic Hierarchy Process
}

\section{Liu Chuncao}

Institute of Economics, Shanghai University, Shanghai, China

Email address:

heigirlfriend@126.com

${ }^{*}$ Corresponding author

\section{To cite this article:}

Liu Chuncao. Evaluation Model of Venous Industry Park Location Based on Fuzzy Analytic Hierarchy Process. International Journal of Economics, Finance and Management Sciences. Vol. 4, No. 6, 2016, pp. 337-343. doi: 10.11648/j.ijefm.20160406.14

Received: August 18, 2016; Accepted: October 12, 2016; Published: November 3, 2016

\begin{abstract}
Vein Industry park location is a significant aspect of the circular economy system. Thus we need an appropriate method. In order to solve this issue, Analytical Hierarchy Process (AHP) method and fuzzy analytic hierarchy process were combined to establish an evaluation system in this paper, which has higher application value.
\end{abstract}

Keywords: Venous Industry, AHP, Fuzzy Analytic Hierarchy Process

\section{Introduction}

Vein Industry which is the industry of garbage collection and recycling, is also called Vein Economy or the Quaternary Sector of Industry. The essence of Vein Industry is using the idea of circular economy to organically coordinate two common issues in world development nowadays, which are waste excessive and resource shortage. Turning waste into treasure, through recycling of waste, makes the natural resources take a back seat in resource supply in the end, so the natural resource could enter a state of real virtuous cycle. Vein Industry Park refers to building an ecological park leading by Vein Industry, which turning traditional linear economic mode of "resource-product--waste" to closed-loop economic mode of "resource-product--re-resource" as much as possible, turning the household and industry waste into resource then reuse. In China now regard Vein industry as an relative effective way to improve circular economy. So the related research on Vein Industry Location is of great practical value.

At present, analytical methods (such as calculus model, linear model, integer models), simulation methods (such as Monte Carlo simulation method) and heuristic methods (such as ant colony algorithm) and other analytical methods are applied to solve the location problem of facility. Evaluation criteria for these analysis methods consists of the cost of building facilities, land prices, storage capacity, transportation costs and the number of other factors, in order to explicit the value to find the most efficient facility location.

In practice, evaluation criteria usually can not be quantified, no precise value to be assessed and judged. Facility location and decision-making process filled with uncertainty, the above methods will induce loss of partial information, and easily lead to making mistakes.

AHP is a model and method, to deal with complex systems that are difficult to quantified, the principle is based on the nature of the problems and the objectives to be achieved, the problem is decomposed into different factors, and in accordance with inter-related factors and affiliation between the different levels of aggregation combination of factors. Forming a multilevel analysis of the structure model, making problems eventually become the relative important or the relative merits of determining value order of the scheduled from the lowest layer (for decision scheme, measures, etc.) relative to top (general objectives). Although, analytic hierarchy process can be possible to establish a variety objectives and factors, but the AHP can not effectively separated the differences between the criteria and is sensitive to subjective factors.

Fuzzy comprehensive evaluation method is an evaluation method based on fuzzy mathematics, which use fuzzy mathematics to evaluate things restricted by various factors; the principle is using fuzzy transformation theory and the theory of maximum membership degree. Make comprehensive evaluation in considering all factors relevant 
to the object. Fuzzy comprehensive evaluation method is quantitative mathematical approach to deal with the phenomenon of fuzziness. The fuzzy comprehensive evaluation method is a method which can convert qualitative evaluation into quantitative evaluation. If integrated analytic hierarchy process and fuzzy comprehensive evaluation method, to quantify the qualitative indicators, we could analyze a more comprehensive analysis of the problem, considering more factors to decide facility location.

Fuzzy analytic hierarchy process is combined with the analytic hierarchy process and fuzzy comprehensive evaluation method, which is quantitative, objectivity and inclusive, it is a kind of more adaptable decision method. When we confront a lot of evaluation objects, evaluation accuracy is not high; we can directly use the fuzzy comprehensive evaluation method for each object, and then calculate the relative membership degree value, using analytic hierarchy process to determine the weight of each factor. The main steps of the fuzzy analytic hierarchy process are as follow: first, to establish a hierarchy index system, and then calculate the weight of each factor by the analytic hierarchy process, and then use fuzzy comprehensive evaluation method to determine the membership degree of each scheme index with membership degree, finally synthetic method to calculate the final assessment of the value. For the vein industrial park's location, the fuzzy analytic hierarchy process can better analyze the influence of various factors for the overall goal, in the process, through the calculation of computer testing consistency, in the largest extent, we can determine the best way to determine venous industrial location.

\section{Literature Review}

Dong Yanping anglicized the characteristics of AHP and Fuzzy comprehensive evaluation method, and proposed fuzzy analytic hierarchy process, considering the features of Logistics Distribution Center Location. This method improved the efficiency of decision-making, applying relative membership degree of Fuzzy comprehensive evaluation method to AHP [1].Cao Yang established a chain store location model by AHP, anglicizing the factors which influenced the location decisions of chain stores. He proved the effectiveness as a reference for Chain Store Location through a case analysis [2]. Fan Lifang, Jiang Haobin and Chen Kunshan anglicized the characteristics of AHP and Fuzzy comprehensive evaluation method, and proposed fuzzy analytic hierarchy process, considering the features of Logistics Distribution Center Location. This method improved the efficiency of decision-making, applying relative membership degree of Fuzzy comprehensive evaluation method to AHP. Cases analysis proved the effectiveness of Distribution Center Location [3]. Chen Shidong, $\mathrm{He} \mathrm{Yu}$ established evaluation index system of options, considering main factors that influence Logistics Park, major factor Logistics Park. They obtained the weights of various factors via Fuzzy analytic hierarchy process to provide the basis for specific programs, which made the decision of Logistics Park location more efficiently and more rationally [4]. Bai Hongwei, Guo Jingfei established evaluation model combing the AHP and Fuzzy comprehensive evaluation method via studies on the location of large industrial enterprises, and noted that this evaluation method played a very meaningful role in decision-making of investors which are Service orientation or intermediate orientation [5]. YU Wenjin, LIU Kai compared the difference between the traditional transport node and logistics center and pointed out the significance and particular feature of Logistic Center Location. They found that ANP, which is the extension from AHP, can analyze the influence factors and internal relations of the location of logistics center more comprehensively from the combination of the outside dynamic environment and internal condition [6]. Ding Liqun, Li Yongzhou took our country some third party physical distribution company's selected location as a case, through the link compared to the law, appraised mathematical models fuzzily and so on law, transportation resources, physical distribution equipment, land resource and so on rigid the essential factors and the human resources is elasticity essential factor effective union, launches the allocation center with emphasis the selected location and the system plane layout question research. Through the discussion about the traffic structure of the development of transport [7], Li Weida analyzed its evolution theoretically [8]. The necessity and feasibility of optimization of regional traffic and transportation structures were analyzed by Zhu Jianmei and Run Haifeng. An optimization indexing system were proposed, and then an optimization model for describing regional traffic and transportation structures was derived that was a combination of qualitative and quantitative analyses. This study was to provide a clew to optimize regional traffic and transportation systems that were usually very complicated [9]. In the study of QiuKun, SongJing and ZhangMin, performance target was classified to different levels by the method of Analytic Hierarchy Process (AHP) according to the different influence elements. Then, based on qualitative and quantitative analysis, the performance evaluation index system and the evaluation model were constructed for the large and medium scale biogas project adopting fuzzy comprehensive evaluation method. And the constructed index system and the evaluation model were applied to the evaluation of 105 large and medium scale biogas projects distributed in five provinces of western China [16].

Nie Yongyou discusses the structure of venous industry, promoting the development of venous industry [11]. Chen Zhenhua, Yuan Jiuyi and Pan Feng introduced the origin of the venous industry, as well as the basic concept and content of the standards for venous industry based on eco-industrial parks. Some existing problems were pointed out, through the analysis of domestic and overseas practices and literatures, recommendations to improve standards were given, and then the deficiency in the work were summed up [13]. After analyzing the development experiences of venous industry in 
Germany and Japan, Qin Haixu, Fang Yuaqiu and Xia Yuanfen brought forward that developing venous industry in China mainly depends on sound legal system, well policy system, widely environmental education, government green purchase system and recycling organization, and emphasized the importance of environmental education especially. It can also provide references for venous industry development in China [14]. After combining with the concept and characteristics of arterial and venous industry, Wang Jun, Yue Siyu, Qiao Qi raised direction in the future and major research for venous industry to solve its main problems [15].

\section{Factors Analysis of Vein Industrial Park Location}

As the key in the circular economy, Vein Industry park location, which is constrained by the industry particularity, should determine the facilities location evaluation system and analytic hierarchy structure model in six aspects :Natural Environment factors, Economic factors, Social factors, Political factors, Transportation Environment factors, technical momentum factors..

\subsection{The Natural Environment Factors}

the requirements of living garbage, industrial solid waste vein industrial location: should be located dominant wind downwind, away from water source, be away from the residential area should be more than $500 \mathrm{~m}$,also we should choose in the higher terrain, plains, Located 50-year flood level above, should choose a simple geological structure, no other geological hazard areas.

the requirements of electromechanical vein industrial location: should be located dominant wind downwind, away from water source, be away from the residential area should be greater than $800 \mathrm{~m}$, and Should choose in the terrain landform areas, plains, Located 100-year flood level above, should choose a relatively simple and stable geological structure without fault.

\subsection{Economic Factors}

Aiming to maximize the profit, vein industrial park must analyze the local land prices and supply, the distance of the raw materials' source, water source, electricity and fuel supplies. The costs and quality of labor, Supply of telecommunications facilities, the distance between other industry park and etc, which determine the cost of Vein Industrial Park. Reduce the cost as much as possible satisfied the long-term interests of the enterprise.

\subsection{Social Factors}

Residents' Attitude and cultural tendencies played a certain influence on the development of vein Industry Park.

\subsection{Political Factors}

Political factors have a huge impact on the development of venous industry. Therefore, vein Industry park location must be carefully analyzed considering Environmental Protection Law and other laws and regulations restrict, Investment incentives, Government efficiency, Long-term planning goals and etc.

\subsection{Transportation Environment Factors}

If the traffic is convenient, if the position is superior, is also an important factor for vein industry location.

\subsection{Technical Factors}

Reliability of the function and the complement of function represent the industrial production technology level of the vein industrial. The higher the level of industrial production technology, the higher the yield industrial, production costs can be reduced as much as possible, it can make enterprise to get more producer surplus, gain more benefits, it is conducive to the long-term development of the enterprise.

\section{Evaluation Model of Venous Industry Park Sitting Based on Fuzzy Analytic Hierarchy Process}

the main steps of Fuzzy analytic hierarchy process (AHP) are as follows: Firstly, establish the hierarchical structure of the evaluation index system; secondly, calculate the weight of each factor with the analytic hierarchy process (AHP); thirdly, use fuzzy comprehensive evaluation method to determine the membership degree of each scheme index; and then combine the membership degrees to calculate the final evaluation values, which determine the best solutions.

\subsection{Establish Evaluation Index System}

Usually, we define the hierarchical structure of the evaluation index system via target layer, criterion layer and scheme layer, which criterion layer depending on the circumstances can be divided into sub-criteria layer, the second criterion layer, and so on.

Table 1. System Diagram of the location of Vein Industry Park.

\begin{tabular}{|c|c|}
\hline target layer & scheme layer \\
\hline $\begin{array}{l}\text { The optimal Vein Industry } \\
\text { park location O } \\
\text { criterion layer }\end{array}$ & $\begin{array}{l}\text { The location of Vein Industry Park to be } \\
\text { evaluated } \\
\text { sub-criteria layer } \\
\text { Topographic and geologic A1 }\end{array}$ \\
\hline Natural Environment & Weather and wind direction $\mathrm{A} 2$ \\
\hline Indicators A & $\begin{array}{l}\text { Water source A3 } \\
\text { drain and residue treatment A4 }\end{array}$ \\
\hline Economic indicators B & $\begin{array}{l}\text { Land price and supply B1 } \\
\text { The distance of the raw materials' source B2 } \\
\text { water source, electricity and fuel supplies B3 } \\
\text { The costs and quality of labour B4 } \\
\text { Supply of telecommunications facilities B5 } \\
\text { the distance between other industry park B6 }\end{array}$ \\
\hline Social factors index $\mathrm{C}$ & $\begin{array}{l}\text { Residents' Attitude and cultural tendencies } \\
\text { C1 }\end{array}$ \\
\hline Political factors index D & $\begin{array}{l}\text { Environmental Protection Law and other } \\
\text { laws and regulations restrict D1 }\end{array}$ \\
\hline
\end{tabular}




\begin{tabular}{ll}
\hline target layer & scheme layer \\
\hline & $\begin{array}{l}\text { Investment incentives D2 } \\
\text { Government efficiency D3 } \\
\text { Long-term planning goals D4 }\end{array}$ \\
$\begin{array}{l}\text { Transportation } \\
\text { Environment Indicators E } \\
\text { Technical momentum } \\
\text { indicator F }\end{array}$ & $\begin{array}{l}\text { Highway convergence situation E1 } \\
\text { The complete extent of the function F1 } \\
\text { the Reliability of function F2 }\end{array}$ \\
\hline
\end{tabular}

Establish all levels of factors indexes are as follows :( the meaning of each letter is described in table 1). Plan of the location of Vein Industry Park $\mathrm{O}=\{\mathrm{A}, \mathrm{B}, \mathrm{C}, \mathrm{D}, \mathrm{E}, \mathrm{F}\}$ (the first layer). $\mathrm{A}=\{\mathrm{A} 1, \mathrm{~A} 2, \mathrm{~A} 3, \mathrm{~A} 4\} ; \quad \mathrm{B}=\{\mathrm{B} 1, \mathrm{~B} 2, \mathrm{~B} 3, \mathrm{~B} 4, \mathrm{~B} 5, \mathrm{~B} 6\}$; $\mathrm{C}=\{\mathrm{C} 1\} ; \quad \mathrm{D}=\{\mathrm{D} 1, \mathrm{D} 2, \mathrm{D} 3, \mathrm{D} 4\} ; \quad \mathrm{E}=\{\mathrm{E} 1\} ; \quad \mathrm{F}=\{\mathrm{F} 1, \mathrm{~F} 2\}$ (the second layer).

\subsection{Establish Alternative Sets}

Alternative sets are a collection of overall sets of the judgers' possible evaluation results about evaluation object. The rating of various levels' factors is as follows: Very favorable, favorable, in general, less favorable and unfavorable.

Reviews set $\mathrm{V}=\{$ Very favorable $\mathrm{v} 1$, favorable $\mathrm{v} 2$, general v3, less favorable v4 and unfavorable v5 .

\subsection{Determine the Weight of Evaluation Factors}

Each factors in evaluation factors set has a different status and role about the "objective evaluation". Each evaluation factors occupy different proportion in comprehensive evaluation, which are called weights. When we use fuzzy comprehensive evaluation, weights have a huge impact on the final results of the evaluation, which different weights sometimes get completely different conclusions. There are many ways to determine the weight value, such as Delphi method, AHP or other methods. Which method is the best way depends on the complexity of the system and the real work. According to the principles of fuzzy analytic hierarchy process, analytic hierarchy process can determine the weight of each impact factor.

Evaluation index system contains six indicators: Natural Environment Indicators, Economic indicators, Social factors index, Political factors index, Transportation Environment Indicators, technical momentum indicator. Though we can not tell these indicators' pros and cons directly, respective importance weights can be determined by pair wise comparison using sequential method. The specific calculation process is as follows:

Firstly do a top-down comparative evaluation of two adjacent elements, and then define the comparative evaluation result of the above evaluation factors as a tentative importance factor. The importance of the natural environment indicator $\mathrm{A}$ is 0.4 times the importance of economic indicators B; similarly, B is 3.0 times the $\mathrm{C}$; $\mathrm{C}$ is $0.5 \mathrm{D}$, E, is 0.5 times $\mathrm{D}, \mathrm{E} F$ is 0.5 times.

Modification coefficient of the tentative importance factors: Define the last index-technical factors index was 1.0. Due to the importance of $\mathrm{E}$ is 2.0 times of the importance of $\mathrm{F}$, the modification coefficient of $\mathrm{E}$ is $0.5 * 1=0.5$. Similarly, all modification coefficients of each evaluation index can be confirmed.

The sum of the calculation of modification coefficient of the tentative importance factors was 2.4.Each modification coefficient of the tentative importance factors divide the sum respectively, which are so called the importance of weight.

The weight of the six factors by sequential method $\mathrm{F}$ is: $\mathrm{f}=(0.06,0.16,0.05,0.10,0.21,0.42)$.

Table 2. Table of the weight of each index's importance.

\begin{tabular}{llll}
\hline Evaluation index & A tentative importance factor & $\begin{array}{l}\text { Modification coefficient of the } \\
\text { tentative importance factors }\end{array}$ & The importance of weight \\
\hline A Natural Environment Indicators & 0.4 & 0.15 & 0.06 \\
B Economic indicators & 3.0 & 0.375 & 0.16 \\
C Social factors index & 0.5 & 0.125 & 0.05 \\
D Social factors index & 0.5 & 0.25 & 0.10 \\
E Transportation Environment Indicators & 0.5 & 0.5 & 0.21 \\
F Technical momentum indicator & & 1.0 & 0.42 \\
total & & 2.4 & 1.0 \\
\hline
\end{tabular}

The concrete solving process of site evaluation model

Assume there are 4 experts, the scores are showed in table 3:

Table 3. Table of weight and scores of different layers.

\begin{tabular}{|c|c|c|c|c|c|c|c|c|}
\hline The first layer index & weight & The second layer index & weight & Very favorable v1 & favorable v2 & general v3 & less favorable v4 & unfavorable v5 \\
\hline \multirow{4}{*}{$\begin{array}{l}\text { Natural Environment } \\
\text { Indicators A }\end{array}$} & \multirow{4}{*}{0.06} & $\begin{array}{l}\text { Topographic and geologic } \\
\text { A1 }\end{array}$ & 0.2 & 2 & 5 & 2 & 1 & 0 \\
\hline & & $\begin{array}{l}\text { Weather and wind direction } \\
\text { A2 }\end{array}$ & 0.3 & 3 & 4 & 1 & 1 & 0 \\
\hline & & Water source A3 & 0.2 & 3 & 5 & 2 & 1 & 0 \\
\hline & & drain and residue treatment & 0.3 & 2 & 5 & 1 & 1 & 0 \\
\hline
\end{tabular}




\begin{tabular}{|c|c|c|c|c|c|c|c|c|}
\hline The first layer index & weight & The second layer index & weight & Very favorable v1 & favorable v2 & general v3 & less favorable v4 & unfavorable v5 \\
\hline \multirow{7}{*}{ Economic indicates B } & \multirow{7}{*}{0.16} & $\mathrm{~A} 4$ & & & & & & \\
\hline & & Land price and supply B1 & 0.2 & 1 & 3 & 4 & 1 & 1 \\
\hline & & $\begin{array}{l}\text { The distance of the raw } \\
\text { materials' source B2 }\end{array}$ & 0.1 & 2 & 3 & 3 & 2 & 1 \\
\hline & & $\begin{array}{l}\text { water source, electricity } \\
\text { and fuel supplies B3 }\end{array}$ & 0.2 & 3 & 4 & 4 & 1 & 1 \\
\hline & & $\begin{array}{l}\text { The costs and quality of } \\
\text { labor B4 }\end{array}$ & 0.1 & 1 & 4 & 2 & 3 & 0 \\
\hline & & $\begin{array}{l}\text { Supply of } \\
\text { telecommunications } \\
\text { facilities B5 }\end{array}$ & 0.2 & 1 & 4 & 2 & 0 & 1 \\
\hline & & $\begin{array}{l}\text { the distance between other } \\
\text { industry park B6 }\end{array}$ & 0.1 & 2 & 2 & 2 & 2 & 1 \\
\hline Social factors index $\mathrm{C}$ & 0.05 & $\begin{array}{l}\text { Residents' Attitude and } \\
\text { cultural tendencies C1 } \\
\text { Environmental Protection }\end{array}$ & 0.8 & 3 & 4 & 3 & 1 & 1 \\
\hline \multirow{4}{*}{$\begin{array}{l}\text { Political factors index } \\
\text { D }\end{array}$} & \multirow{4}{*}{0.1} & $\begin{array}{l}\text { Law and other laws and } \\
\text { regulations restrict D1 }\end{array}$ & 0.3 & 2 & 4 & 2 & 2 & 0 \\
\hline & & Investment incentives D2 & 0.4 & 3 & 3 & 3 & 1 & 0 \\
\hline & & Government efficiency D3 & 0.2 & 2 & 2 & 4 & 1 & 1 \\
\hline & & $\begin{array}{l}\text { Long-term planning goals } \\
\text { D4 }\end{array}$ & 0.2 & 2 & 4 & 2 & 1 & 1 \\
\hline $\begin{array}{l}\text { Transportation } \\
\text { Environment } \\
\text { Indicators E }\end{array}$ & 0.21 & $\begin{array}{l}\text { Highway convergence } \\
\text { situation E1 }\end{array}$ & 1.0 & 2 & 5 & 2 & 1 & 0 \\
\hline \multirow{2}{*}{$\begin{array}{l}\text { technical momentum } \\
\text { indicator } \mathrm{F}\end{array}$} & \multirow{2}{*}{0.42} & $\begin{array}{l}\text { The complete extent of the } \\
\text { function F1 }\end{array}$ & 0.4 & 1 & 3 & 3 & 2 & 1 \\
\hline & & $\begin{array}{l}\text { the Reliability of function } \\
\text { F2 }\end{array}$ & 0.5 & 2 & 4 & 2 & 1 & 1 \\
\hline
\end{tabular}

Firstly, normalized processes the scores of the table, we got R1:

$$
\begin{aligned}
\mathrm{R} 1 & =\left|\begin{array}{lllll}
0.2 & 0.5 & 0.2 & 0.1 & 0 \\
0.3 & 0.4 & 0.1 & 0.1 & 0 \\
0.3 & 0.5 & 0.2 & 0.1 & 0 \\
0.2 & 0.5 & 0.1 & 0.1 & 0
\end{array}\right| \\
\mathrm{R} 2 & =\left|\begin{array}{lllll}
0.1 & 0.3 & 0.4 & 0.1 & 0.1 \\
0.2 & 0.3 & 0.3 & 0.2 & 0.1 \\
0.3 & 0.4 & 0.4 & 0.1 & 0.1 \\
0.1 & 0.4 & 0.2 & 0.3 & 0 \\
0.1 & 0.4 & 0.2 & 0 & 0.1 \\
0.2 & 0.2 & 0.2 & 0.2 & 0.1
\end{array}\right| \\
\mathrm{R} 3 & =\left|\begin{array}{lllll}
0.3 & 0.4 & 0.3 & 0.1 & 0.1
\end{array}\right| \\
\mathrm{R} 4 & =\left|\begin{array}{lllll}
0.2 & 0.4 & 0.2 & 0.2 & 0 \\
0.3 & 0.3 & 0.3 & 0.1 & 0 \\
0.2 & 0.2 & 0.4 & 0.1 & 0.1 \\
0.2 & 0.4 & 0.2 & 0.1 & 0.1
\end{array}\right| \\
\mathrm{R} 6 & =\left|\begin{array}{lllll}
0.1 & 0.3 & 0.3 & 0.2 & 0.1 \\
0.2 & 0.4 & 0.2 & 0.1 & 0.1
\end{array}\right|
\end{aligned}
$$

According to the formula, comprehensive evaluation index of the second layer could be obtained: 


$$
\begin{aligned}
& \mathrm{A}=\left|\begin{array}{llll}
0.2 & 0.3 & 0.2 & 0.3
\end{array}\right| *\left|\begin{array}{ccccc}
0.2 & 0.5 & 0.2 & 0.1 & 0 \\
0.3 & 0.4 & 0.1 & 0.1 & 0 \\
0.3 & 0.5 & 0.2 & 0.1 & 0 \\
0.2 & 0.5 & 0.1 & 0.1 & 0
\end{array}\right|=(0.25,0.47,0.14,0.1,0) ;
\end{aligned}
$$

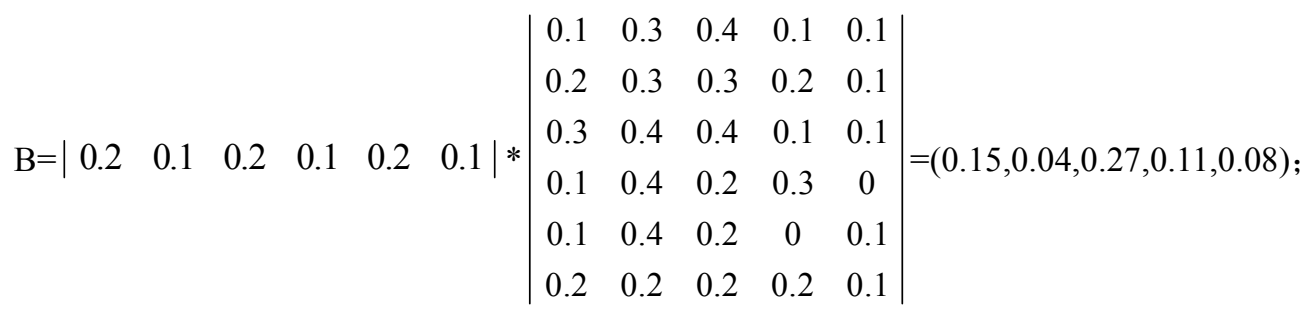

$$
\begin{aligned}
& \mathrm{C}=|0.8| *|0.3 \quad 0.4 \quad 0.3 \quad 0.1 \quad 0.1|=(0.24,0.32,0.24,0.08,0.08) \text {; } \\
& \mathrm{D}=\left|\begin{array}{llll}
0.2 & 0.3 & 0.2 & 0.3
\end{array}\right| *\left|\begin{array}{ccccc}
0.2 & 0.4 & 0.2 & 0.2 & 0 \\
0.3 & 0.3 & 0.3 & 0.1 & 0 \\
0.2 & 0.2 & 0.4 & 0.1 & 0.1 \\
0.2 & 0.4 & 0.2 & 0.1 & 0.1
\end{array}\right|=(0.23,0.33,0.27,0.12,0.05) \text {; } \\
& \mathrm{E}=|1.0| *|0.2 \quad 0.5 \quad 0.2 \quad 0.1 \quad 0|=(0.2,0.5,0.2,0.1,0) \text {; } \\
& \mathrm{F}=\left|\begin{array}{ll}
0.4 & 0.5
\end{array}\right| *\left|\begin{array}{ccccc}
0.1 & 0.3 & 0.3 & 0.2 & 0.1 \\
0.2 & 0.4 & 0.2 & 0.1 & 0.1
\end{array}\right|=(0.14,0.32,0.22,0.13,0.09) \text {; }
\end{aligned}
$$

So, the fuzzy relation matrix from $\mathrm{O}$ to $\mathrm{L}$ :

$$
\mathrm{R}=\left|\begin{array}{ccccc}
0.25 & 0.47 & 0.14 & 0.1 & 0 \\
0.15 & 0.04 & 0.27 & 0.11 & 0.08 \\
0.24 & 0.32 & 0.24 & 0.08 & 0.08 \\
0.23 & 0.33 & 0.27 & 0.12 & 0.05 \\
0.2 & 0.5 & 0.2 & 0.1 & 0 \\
0.14 & 0.32 & 0.22 & 0.13 & 0.09
\end{array}\right|
$$

According to the formula, comprehensive evaluation index of the first layer could be obtained:

$$
\mathrm{O}=\left|\begin{array}{llllll}
0.06 & 0.16 & 0.05 & 0.1 & 0.21 & 0.42
\end{array}\right| *\left|\begin{array}{ccccc}
0.25 & 0.47 & 0.14 & 0.1 & 0 \\
0.15 & 0.04 & 0.27 & 0.11 & 0.08 \\
0.24 & 0.32 & 0.24 & 0.08 & 0.08 \\
0.23 & 0.33 & 0.27 & 0.12 & 0.05 \\
0.2 & 0.5 & 0.2 & 0.1 & 0 \\
0.14 & 0.32 & 0.22 & 0.13 & 0.09
\end{array}\right|=(0.1748,0.323,0.225,0.1152,0.0596)
$$

The assessment of this vein Industrial Park site $\mathrm{O}$ was: the level of "Very favorable" was $17.48 \%$, the level of "favorable" was $32.3 \%$, the level of "general" was $22.5 \%$, and the level of "less favorable" was 11.52 percent, the level of "favorable" of $5.96 \%$.

\section{Conclusion}

In this paper, compared with advantages and disadvantages of Analytic hierarchy process and Fuzzy comprehensive evaluation method, Fuzzy analytic hierarchy process was raised, which could be used to solve the problem of Vein
Industry Location. Via this method, subjective assumptions could be avoided; better cognition of each factor's impact on target could be realized scientifically and effectively. This kind of method for Vein Industry Location has great reference value and practical significance.

\section{References}

[1] Dong Yanping. The Study on Logistics Distribution Center Location Based on Fuzzy Analytic Hierarchy Process [A]. Science \& Technology Monthly, 2010, 10：92-100. 
[2] Cao Yang. The Study on Chain Store Location Based on Fuzzy Analytic Hierarchy Process [A]. Market Modernization. 2009, 11: 48-49.

[3] Fan Lifang, Jiang Haobin, Chen Kunshan. The Study on Distribution Center Location Based on Fuzzy Analytic Hierarchy Process [A]. Transportation Systems Engineering and Information Technology. 2006, 2: 107-110.

[4] Chen Shidong, He Yu. Application to Logistics Park Based on Fuzzy Analytic Hierarchy Process [A]. Logistics Technology. 2010, 7: 36-38.

[5] Bai Hongwei, Guo Jingwen. Evaluation of Industrial Enterprises Siting [A]. TECHNOLOGY \& DEVELOPMENT. 2011, 23: 35-37.

[6] Yu Wenjin, Liu Kai. The Study on Logistics Center Location Based on ANP [J]. Journal of Transportation Systems Engineering and Information Technology, 2006(5).

[7] Ding Liqun, Li Yongzhou. The Study on Logistics Distribution Center Location Based on Fuzzy Evaluation Method----in Case of Wuhan Iron Yitong Logistics [J]. Logistics Engineering and Management, 2009(12).

[8] Li Weida. Theoretical analysis of the evolution of the structure of Transport Law [J]. Shipping Management, 2000(7).
[9] Zhu Jianmei, Run Haifeng, Wang Bo. Optimization Study on Area Transportation Structure [J]. Journal of XiNan Jiaotong University, 2003(4).

[10] Guo Ciocong, Chen Gang. Soft Computing of Information Science [M]. Shen Yang: Northeastern University Press.

[11] Nie Yongyou. Vein Industry Exploration under Cyclic Economic Conditions [J]. South Economics, 2005, (12).

[12] State Environmental Protection Administration. Standard of Vein Industry Park [Z]. 2006- 06- 02.

[13] Chen Zhenhua, Yuan Jiuyi, Pan Feng, Study on Standard of Vein Industry Park [J]. Anhui Agricultural Sciences, 2009, 37(8).

[14] Qin Haixu, Wan Yuqiu, Xia Yuanfen. Development of Vein Industry Park in German and Japan and Reference to China [J]. Environmental Science and Management, 2007, (6).

[15] Wang Jun, Yue Siyu, Qiao Qi, Development and Future Development of Vein Industry Park in China [J]. Environmental Protection, 2006, (11B).

[16] Qiu Kun, Song Jing, Pu Xiaodong, Zhang Min. Evaluation of large biogas Performance based on Analytic hierarchy process and fuzzy mathematics comprehensive Analytical Method [A]. China Biogas, 2016, 34(1). 